\title{
Allylcyclohexylamine functionalized siloxane polymer and its phase separated blend as pervaporation membranes for 1,3-propanediol enrichment from binary aqueous mixtures
}

\author{
Baishali Kanjilal ${ }^{1}$, Iman Noshadi ${ }^{2}$, Jeffrey R. McCutcheon ${ }^{2}$, Alexandru D. Asandei ${ }^{1,3}$, Richard S. \\ Parnas ${ }^{1,2,3^{*}}$ \\ ${ }^{1}$ Institute of Materials Science, University of Connecticut, 97, N. Eagleville Rd. Storrs, CT \\ 06269, USA \\ 2 Department of Chemical and Biomolecular Engineering, University of Connecticut, 191 \\ Auditorium Rd. Storrs, CT 06269, USA \\ ${ }^{3}$ Department of Chemistry, University of Connecticut, 55, N. Eagleville Rd. Storrs, CT 06269, \\ USA
}

*Corresponding Author, Address: Institute of Materials Science, University of Connecticut,
Storrs, CT 06269, United States. Tel.: +1 8604869060. Fax: (860) 486-2959 E-mail:
rparnas@ims.uconn.edu

\begin{abstract}
This work reports the synthesis of a novel allylcyclohexylamine functionalized siloxane and its phase separated blend with styrene-butyl acrylate copolymer and their application for pervaporative enrichment of 1,3-propanediol from dilute aqueous solutions. The phase separated blend allowed for the recovery of mechanical strength lost due to functionalization without loss in separation performance. Separation factors of $9-15$ were achieved with functionalization levels of 50-90\%, while 1,3-propanediol flux was $5.5-5.8 \mathrm{~g} / \mathrm{m}^{2} \mathrm{~h}$. Separation efficiency increased with functionalization and decreased with increasing temperature and feed concentration. Solution diffusion model was used to compute the overall mass transfer coefficients, concentration polarization and intrinsic material mass transport properties. The overall mass transfer coefficient for 1,3-propanediol was between $1.0 \cdot 10^{-7}-1.4 \cdot 10^{-7} \mathrm{~m} / \mathrm{s}$ while the boundary layer mass transfer coefficient ranged from $510^{-7} \mathrm{~m} / \mathrm{s}$ to $18 \cdot 10^{-7} \mathrm{~m} / \mathrm{s}$ indicating the dominance of the membrane on the transport resistance. A computation of Hansens solubility parameters by a group contribution method was carried out to underscore the results. The membrane, with its good cost/performance tradeoff and excellent mechanical integrity, offers the possibility of fabrication into modules and scale up.
\end{abstract}

Keywords: Allylcyclohexylamine siloxanes, Pervaporation, 1,3-propanediol, Solution-Diffusion 


\section{Introduction}

The fermentation of crude glycerol to 1,3-propanediol (1,3-PD) provides value to the current over capacity of waste industrial glycerol [1]. The separation of 1,3-PD accounts for a major portion of the total production cost and is a process bottleneck [2]. The separation bottleneck is the enrichment of 1,3-PD concentration from dilute starting concentration in the aqueous mixture [2 - 4]. The complexity of separation is compounded by its high water affinity [2, 5]. Several separation techniques have been reported which attempted to enrich 1,3-PD concentrations from aqueous mixtures and broths with concomitant energy, cost and applicability limitations [5 - 18]. For instance, high separation factors have been reported with an ionic liquid based supported liquid membrane (SLM), but the ionic liquid is extremely expensive [18]. However, a highly functional material needs to be designed into a system for industrial application to get adequate financial return on process investment. This paper illustrates the development and application of a novel siloxane based polymer membrane with a balance of cost and performance. Additionally, siloxane based polymers are relatively fouling resistant and appropriate for use with fermentative processes $[19,20]$.

Amongst separation processes explored for 1,3-PD enrichment from dilute aqueous mixtures and broths, distillation consumes large amounts of energy given the large excess of water [6-8]. Solvent extraction with sequential steps using simple solvents to complex methanol-phosphate blends has been investigated [5,9,10]. However, 1,3-PD is only partly partitioned into a hydrophobic solvent phase rendering the methods unfeasible [5]. Chromatography, while achieving excellent separation from other metabolites, results in an extremely dilute final concentration [11-13]. Reactive extraction converts 1,3-PD to a less water soluble compound which is first extracted and then converted back but suffers from complications of multiple unit operations, side reactions and yield losses [14,15]. Studies of pervaporative enrichment of 1,3PD have been less numerous than other techniques [16-18]. Works with Na-ZSM-5 and X-type zeolite membrane pervaporations have only reported selectivity over broth components other than water $[16,17]$. A supported ionic liquid membrane has been used in a ceramic nanofiltration module coated with a PDMS layer exhibiting high 1,3-PD selectivity with aqueous mixtures in batch pervaporation [18]. While pervaporation, like distillation, involves a liquid to vapor phase change, it deals with the minor component using selective membranes. These features reduce 
energy consumption and make pervaporation the most efficient 1,3-PD separating technology [21]. To the best of our knowledge no reports exist on synthesized polymeric structures with continuous pervaporative enrichment of 1,3-PD and with a potential for scale up.

Poly(dimethylsiloxane) (PDMS) is an appropriate material for membrane pervaporation due to its hydrophobic character, good thermal, chemical and mechanical stability, low base material cost and ease of fabrication [22]. However, PDMS has very little affinity for 1,3-PD and hence needs to be modified or functionalized to improve selectivity. Studies on PDMS membranes functionalized with a variety of organofunctional side chains have been carried out for pervaporative separation of volatile organics such as phenol and cresol from water [23-25].

This paper reports a novel membrane structure for continuous pervaporative enrichment of 1,3PD from binary aqueous feed solutions. The structure is based on allylcylcohexylamine (ACA) functionalized poly(hydromethylsiloxane) (PHMS). The hydrosilylated PHMS is fabricated into a membrane structure on a porous polyethylene support using two methods. In one, it is crosslinked with a high molecular weight hydroxyl terminated PDMS while the other method entails the formation of a microphase separated semi interpenetrating polymeric network (SIPN) blend with a high molecular weight styrene-butyl acrylate (SBA) copolymer. The properties of functionalized PHMS and the membrane forming materials are characterized. The membranes are applied for the continuous pervaporative enrichment of 1,3-PD from dilute binary aqueous mixtures. The performance of the system is analyzed with respect to levels of functionalization, membrane fabrication method and various process parameters. The overall mass transfer coefficients, concentration polarization and other transport properties were analyzed using the solution diffusion model. In the absence of significant concentration polarization, the intrinsic mass transfer coefficients of the membrane materials were computed. Reasonable fluxes and separation factors were achieved for the membranes in addition to good mechanical stability. These structures may be viable alternatives to conventional purification processes as well as to supported liquid membranes offering a balance between separation performance and material cost in addition to mechanical integrity. The mechanical integrity also makes it possible to fabricate pervaporation modules, including its application in multilayer membranes, for use in continuous processes with concomitant reduction of the energy cost bottleneck pertaining to 1,3PD concentration enrichment. 


\section{Experimental}

\subsection{Materials:}

\subsubsection{PHMS functionalization by hydrosilylation:}

For the hydrosilylation reactions, PHMS of degree of polymerization 35 to 40, ACA and bone dry toluene (<30 ppm water) were purchased from Sigma Aldrich and dried prior to use. The chloroplatinic acid and dibutyl tin dilaurate catalysts were purchased from Sigma Aldrich and used without modification.

Hydroxyterminated poly(dimethylsiloxane) (HPDMS) and tetraethyl orthosilicate (TEOS) were purchased from Sigma Aldrich. These components were passed through a drying column prior to use.

\subsubsection{Styrene-butyl acrylate emulsion polymerization:}

For the styrene-butyl acrylate emulsion polymerization, styrene and butyl acrylate were purchased from Sigma Aldrich and passed through a column of inhibitor remover prior to emulsion polymerization. Potassium persulphate, tert-butyl perbenzoate, sodium bicarbonate and sodium dodecylbenzenesulfonate were purchased from Sigma Aldrich and used without modification.

\subsection{Membrane fabrication and pervaporation feed:}

Porous polyethylene sheets were obtained from Interstate Specialty Products for use as the support sheet for membrane fabrication. The nominal thickness reported was 500 microns with pore diameters of $75-110$ microns and a porosity of $48 \%$. Twenty measurements of thickness indicated the actual thickness was $535 \pm 10$ microns.

1,3 propanediol (1,3-PD), 98\% purity was purchased from Sigma Aldrich and used for the partition coefficient measurements and for preparation of binary mixtures with distilled water as feed solutions for pervaporation experiments.

\subsection{Analytical methods}

${ }^{1} \mathrm{H}$ NMR was carried out to monitor the extent of functionalization of PHMS in the hydrosilylation reaction and to characterize the emulsion polymerized SBA copolymer on a Brucker DMX-500 MHz spectrometer. IR spectra were taken on samples with a Nicolet MagnaIR 560 spectrometer, with $\mathrm{KBr}$ powder being used as background. The molecular weight of the 
functionalized PHMS was determined by GPC with an Agilent 1260 Infinity system using toluene as eluent and narrow molecular weight PDMS from Sigma Aldrich as calibration standards. The molecular weight of the SBA copolymer was determined by GPC using toluene as the eluent and PMMA calibration standards. Thermo-gravimetric analysis was carried out on all the polymers in a TA Instruments Hi-Res 2950 TGA instrument at a ramp of $20^{\circ} \mathrm{C} / \mathrm{min}$ in nitrogen up to a temperature of $800^{\circ} \mathrm{C}$. The thermal transitions of the polymer were determined in TA Instruments Q100 and DSC 2920 instruments under liquid nitrogen cooling. Contact angle measurements were carried out on an Olympus TGHM goniometer. Tensile testing was carried out on rectangular samples of width $10 \mathrm{~mm}$ and thickness $200 \mu$ on an Instron Universal Testing Machine (UTM). A gage length of $25.4 \mathrm{~mm}$ and a cross head speed of $50 \mathrm{~mm} / \mathrm{min}$ was employed to obtain break stress and strain values. Field emission scanning electron microscopy (FESEM) images of the porous polyethylene and composite membrane structures were obtained with a JEOL 6335F field emission scanning electron microscope. The feed and permeate compositions from the pervaporation experiments were analyzed using $0.22 \mu \mathrm{m}$ syringe filtered fermentation samples by gas chromatography (GC) using a DB-FFAP capillary column and an MS detector and a $1 \mu \mathrm{L}$ injection volume. GC injector, detector and initial over temperatures were kept at $240^{\circ} \mathrm{C}, 270^{\circ} \mathrm{C}$, and $40^{\circ} \mathrm{C}$ for 2 minutes respectively.

\subsection{Partition coefficient measurement}

The partition coefficient of 1,3-PD between water and ACA was determined at $30^{\circ} \mathrm{C} .1 \mathrm{ml}$ of a $10 \mathrm{~g} / 1$ 1,3-PD solution was shaken in a vortex mixer with $1 \mathrm{ml}$ of ACA for 15 minutes and left for separation between the water and ACA phases. The 1,3-PD partitioned between the two phases and its concentration in the two phases was computed from GC results of the aqueous phase before and after partitioning. The partition coefficient was calculated based on equation 1 :

$$
K_{p}=\frac{c_{A C A}}{c_{\text {water }}}
$$

\subsection{Synthesis, purification and characterization of ACA functionalized PHMS}

The PHMS was functionalized with ACA by hydrosilylation using the chloroplatinic acid catalyst solution [23-25]. The reaction was carried out in a clean and dry glass pressure tube flushed with high purity argon on a schlenk line. A $25 \mathrm{mg} / \mathrm{ml}$ chloroplatinic acid catalyst solution in isopropanol was prepared. A typical run consisted of $1.5 \mathrm{~g}$ PHMS with varying quantities of ACA, depending upon the targeted extents of substitution, and $1 \mathrm{ml}$ of toluene as solvent. The 
catalyst solution was added to the extent of $5 \mathrm{ml} / \mathrm{ml}$ of reaction volume. The reaction temperature was controlled at $70 \pm 2^{0} \mathrm{C}$. Given the sensitivity of the reaction to moisture and temperature, with hydride elimination occurring at high temperatures and in the presence of moisture, all reagents were thoroughly dried prior to use [23-25]. The reaction was monitored by ${ }^{1} \mathrm{H} \mathrm{NMR}$ in $\mathrm{CDCl}_{3}$ and FTIR. The polymer solution was cooled by immersing the pressure tube in a dry ice and acetone mixture, with a small amount of liquid nitrogen, to facilitate the separation of the functionalized polymer from the solvent and remaining catalyst and unreacted volatiles. The functionalized PHMS was re-dissolved in toluene, the procedure repeated thrice and the remnant toluene solvent removed by rotary evaporation. The polymer was finally washed with ethanol and vacuum dried again. The functionalized polymer was characterized for glass transition temperature and molecular weight by DSC and GPC respectively. The reaction scheme is depicted in Figure 1(a). The NMR and FTIR are depicted in Figures 1(b) and 1(c). The glass transition temperatures and molecular weights are shown in Figures 1(d) and 1(e).

\subsection{Synthesis, purification and characterization of styrene-butyl acrylate copolymer}

A high molecular weight SBA copolymer was synthesized by emulsion polymerization modified from an earlier patented process on pressure sensitive adhesive latex production [26]. The reaction was carried out at $80^{\circ} \mathrm{C}$ in a $250 \mathrm{ml}$ two necked round bottom flask fitted with a reflux condenser with the system being constantly purged with nitrogen. A typical batch consisted of $50 \mathrm{~g}$ deionized water, $0.5 \mathrm{~g}$ potassium persulphate, $0.25 \mathrm{~g}$ sodium bicarbonate, $1 \mathrm{~g}$ sodium dodecylbenzenesulfonate $0.25 \mathrm{~g}$ tert-butyl perbenzoate, $50 \mathrm{~g}$ butyl acrylate and $50 \mathrm{~g}$ styrene. While sodium bicarbonate and sodium dodecylbenzenesulfonate were added beforehand, the monomer mixture was added drop wise over a period of 15 minutes through the second neck. After the monomer addition, the temperature was reduced to $65^{\circ} \mathrm{C}$ and the potassium persulphate and tertbutyl perbenzoate added and the reaction was allowed to run for 2 hours. A silicone rubber tube fitted with a needle was used to blanket the surface of the reaction mixture with nitrogen throughout the $2 \mathrm{~h}$ course of the reaction. At the end of the reaction, the emulsion was flocculated by sodium chloride, the flocculated polymer washed thoroughly and repeatedly, centrifuged and dried at room temperature. The purified polymer was analyzed for composition, thermal transitions and molecular weight by NMR, DSC and GPC respectively.

\subsection{Membrane fabrication and characterization}

\subsubsection{Scheme 1}



PDMS (HPDMS) and TEOS [23, 24]. The HPDMS and TEOS were kept at $10 \%$ and $2 \%$ of the total weight of the mixture respectively. Undiluted dibutyl tin dilaurate catalyst was added to this mixture at $0.1 \%$ by weight of the mixture. A small amount of toluene was added to this mixture to lower its viscosity. A piece of porous polyethylene sheet was soaked in measured quantities of this mixture and the solvent was allowed to evaporate at room temperature over a period of $\sim 24$ hours. The membrane was then allowed to cure at $60^{\circ} \mathrm{C}$ for 4 days to ensure completion of crosslinking and cut to the required shape. Membranes were fabricated using 50\%, $70 \%$ and $90 \%$ ACA functionalized PHMS and were given the nomenclature PDMS_50ACA, PDMS_70ACA and PDMS_90ACA respectively.

\subsubsection{Scheme 2}

In a separate scheme the ACA functionalized PHMS was blended with the emulsion polymerized SBA copolymer and TEOS. The SBA and TEOS were kept at $10 \%$ and $2 \%$ of the total weight while the dibutyl tin dilaurate catalyst was kept at $0.1 \%$ by weight of the mixture. The methods of membrane fabrication and evaluation are the same as above. The nomenclature used for the membrane fabricated with this scheme, employing 90\%ACA functionalized PHMS was SBA_90ACA.

All membranes were evaluated for thickness, viewed under FESEM and used for pervaporation experiments. The membrane forming recipes were separately cast, without the porous support, on a Kapton sheet into 100 micron thick sheets for tensile tests. Pieces of these sheets were used for mass uptake experiments [22] and DSC measurements. The recipes were also cast as a thin layer on clean glass slides for evaluation of water contact angle.

\subsection{Pervaporation experiments}

Pervaporation was carried out in a custom-made membrane holder providing a pervaporation area of $43 \mathrm{~cm}^{2}$. It was fabricated at the Technical Services Facility at University of Connecticut. The feed solutions consisting of 1,3-PD-water binary mixtures were maintained at various temperatures. The feed solutions were recirculated over the membrane on a perforated brass support in the membrane holder by a peristaltic pump, providing varying cross flow rates. The permeate was collected in two parallel cold traps, cooled in a dry ice - acetone bath. A vacuum pump was employed to maintain the permeate side pressure at less than $1 \mathrm{~mm} \mathrm{Hg}$. Permeate 
samples were collected at regular time intervals until steady state was reached. The permeate compositions were analyzed by gas chromatography. The pervaporation equipment used and its schematic are detailed in an earlier work by Li et al 2010 [22]. As in a typical pervaporation run, the slope of the total accumulated permeate mass vs time increased and reached a plateau after steady state was reached by that particular run. The steady states were stable over the many hours of the experiments. The initial transient behavior did not level out to steady state behavior at the same time for each membrane or process condition. The time period required to reach steady state did not appear to correlate with membrane composition or cross flow rate. However, the steady states were achieved slightly faster at higher temperatures.

Pervaporation experiments were carried out with varying membrane recipes, different temperatures, cross flow rates and feed compositions. The average bulk concentration is essential to determine the overall mass transfer coefficient. The pervaporation experiments entailed a broth volume of $1000 \mathrm{ml}, \sim 0.4-0.5 \mathrm{ml}$ of the collected permeate was used for chromatographic analysis. The remaining permeate collected was weighed and returned to the system to maintain the feed concentration at as constant a level as possible. The feed composition was also evaluated from time to time to verify the concentrations of the components. The feed composition was taken to be the average of the initial and final feed compositions as the feed composition changed by less than $2 \%$ of the initial composition for each component. The key performance indicators of the pervaporation experiment were defined by the component fluxes and the separation factor defined as:

$$
\alpha=\frac{J_{p}}{J_{w}} \frac{x_{w}}{x_{p}}
$$

where $J_{p}$ and $J_{w}$ represent the 1,3-PD and water fluxes, and $x_{p}$ and $x_{w}$ represent the feed mass fractions of 1,3-PD and water, respectively.

\section{Results and Discussions}

\subsection{Partition coefficient in amine}

The partition coefficient of 1,3-PD in ACA over water was estimated at $0.5 \pm 0.03$. ACA is a hydrophobic solvent, with a Log $\mathrm{P}_{\mathrm{ow}}$ (octanol - water redistribution coefficient) $\sim 2.2-2.4$, in which 1,3-PD is miscible in all proportions. 


\subsection{Functionalization of PHMS by hydrosilylation - monitoring of reaction and polymer characterization}

Linear, organofunctional polysiloxanes were prepared by the platinum catalyzed reaction of ACA with PHMS as depicted in the reaction scheme in Figure 1(a) [23]. The sensitivity of the reaction to moisture warranted that all components be dried thoroughly prior to reaction [23]. Water reacts with the hydride groups of PHMS producing silanol groups which upon heating crosslink the chains. It was also essential to achieve high levels of functional substitution of the PHMS in order to have the required amount of ACA in the final membrane structure. The degree of substitution is defined as the percentage of $\mathrm{Si}-\mathrm{H}$ bonds substituted with ACA. It was possible to quantitatively substitute the targeted number of $\mathrm{Si}-\mathrm{H}$ bonds in PHMS. The degree of substitution was monitored by the reduction in ${ }^{1} \mathrm{H}$ NMR peak and FTIR peak areas pertaining to the $\mathrm{Si}-\mathrm{H}$ bond and $\mathrm{C}=\mathrm{C}$ bond. The NMR and FTIR figures (Fig. 1(b) and 1(c)) are for a reaction system attempting to substitute $100 \%$ of the $\mathrm{Si}-\mathrm{H}$ bonds in PHMS. The level of ACA functionalization achieved was monitored by comparison of the integrated areas under the peak at $\delta=4.8 \mathrm{ppm}$ ( $\mathrm{Si}-\mathrm{H}$ bond) with that at $\delta=0.2 \mathrm{ppm}$ (-Si-CH-). As the reaction progressed, the latter increased at the expense of the former.

With higher levels of substitution, the reaction became sluggish with time. This can be attributed to steric hindrances with larger degrees of substitution. The purified polymer was characterized for thermal transitions and molecular weight by DSC and GPC as shown in Figures 1(d) \& 1(e). The increase in molecular weight numerically corroborates the quantitative substitution of $\mathrm{Si}-\mathrm{H}$ bonds as seen with NMR. The ACA functionalized polymers retained flow even at high levels of substitution, underscoring the fact that there had been no hydride elimination and hence no undue crosslinking during the reaction. The glass transition increases with increasing functionalization. Beyond 50\% substitution, the rate of increase in $\mathrm{Tg}$ becomes slower. The functionalized polymers were amber colored highly viscous liquids.

\subsection{Styrene-butyl acrylate copolymer characterization}

Emulsion polymerization allowed the attainment of a high molecular weight SBA copolymer. The weight average molecular weight from GPC measurements was 344,365 and Mz of 909,459, with a PDI of 2.95. The glass transition temperature of the polymer obtained was $4.4( \pm 0.3)^{0} \mathrm{C}$. The average copolymer composition was ascertained from the ratios of the area under the peak at 
$\delta=7-7.5 \mathrm{ppm}$ (aromatic proton from styrene) and $\delta=3.8-4 \mathrm{ppm}\left(-\mathrm{O}-\mathrm{CH}_{2}-\right.$ from butyl acrylate). The average molar copolymer composition was $\sim 43 \%$ butyl acrylate and $57 \%$ styrene.

\subsection{Membrane characterization}

The reaction mechanisms of membrane formation for both scheme 1 and scheme 2 are depicted in Figures 2(a) and 2(b). All membranes were evaluated for thickness, viewed under FESEM and used for pervaporation experiments. A representative FESEM, along with a FESEM of the porous polyethylene support sheet, as the inset, is shown in Figure 2(c). The membrane forming recipes, as described in the sections above, wet and fill the pores of the 535 micron porous polyethylene support sheet, forming membranes of total thickness $643 \pm 20$ microns (based on 20 measurements). The fabrication was conducted so that none of the membrane polymer leaked out the bottom of the porous polyethylene. Thus, a dense top layer of membrane polymer of $108 \pm 16$ microns thickness was formed.

The $\mathrm{Tg}$ of the membrane forming recipes (Fig. 2c), as per scheme 1, with hydroxyl terminated PDMS reflected the Tg trends obtained with increasing ACA functionalization of the PHMS as shown in an earlier figure (Fig 1d). In scheme 2, which blended the ACA functionalized PHMS with the high molecular weight SBA copolymer followed by crosslinking the former with TEOS, the existence of a microphase segregation between the siloxane and SBA domains was underscored by the presence of two distinct Tg inflexion regions. The membranes formed using scheme 2 were opaque in appearance versus the translucent appearance of those formed using scheme 1. The membrane material formed as per scheme 2, at the molecular level can be thought of as a semi interpenetrating polymeric network, wherein the TEOS mediated crosslinked ACA functionalized PHMS is interspersed and networked in between the thermoplastic chains of the SBA copolymer. At the same time, the microphase separation means that there exist segregated domains of the two major components in the matrix. This is schematically represented in Fig. 2 d.

The membrane forming recipes were cast as a thin layer on clean glass slides for water contact angle measurements. All membranes were fairly hydrophobic, with water contact angles varying between $99.5^{\circ}$ and $106^{\circ}$ (Fig. 3a.). There appeared to be no correlation to the level of ACA functionalization of the PHMS and the ensuing water contact angle in the membrane recipe. However, the membrane recipe SBA_90ACA, formed with 90\% ACA substituted PHMS 
blended with styrene-butyl acrylate emulsion polymer exhibited a higher water contact angle than other recipes. Super-hydrophobic electrospun non-woven fibrous mats from block copolymers of poly (styrene-b-dimethylsiloxane) have been shown to exhibit water contact angles up to $163^{\circ}$, wherein the super-hydrophobicity was attributed to a microphase separation resulting in differential surface enrichment by the siloxanes [27]. Additionally, superhydrophobic surfaces mimicking lotus leaf properties have been reported on cotton fibers treated with poly (butyl acrylate)-modified CNT [28].

The results of water and 1,3-PD mass uptake experiments are shown in Figure 3b. While there is a slight decrease in water uptake with increasing ACA functionalization of PHMS, the 1,3-PD uptake increases rapidly with increasing ACA loading.

The results of tensile testing are shown in Figure 3c. For the materials made per scheme 1, ACA functionalization adversely affected the break stress and strain. The poor mechanical integrity of these materials precluded their prolonged application in pervaporation studies with varying process conditions. A marked enhancement in tensile strength is obtained by blending the functionalized PHMS with the high molecular weight SBA copolymer (Scheme 2) and allowed for its prolonged usage in pervaporation under varying experimental conditions. The scheme 1 membrane material using unfunctionalized PHMS is an elastomer with a tensile break stress and a tensile break strain of $0.54 \mathrm{MPa}$ and $\sim 640 \%$ respectively. With the inclusion of ACA functionalized PHMS, the stress and strain at break reduced significantly. The break stresses and strains reduce to $0.13 \mathrm{MPa}, 0.098 \mathrm{MPa}$ and $0.051 \mathrm{MPa}$ and $413 \%, 128 \%$ and $43 \%$ with $50 \%, 70 \%$ and 90\% functionalization of PHMS. By blending the 90\% ACA substituted PHMS with SBA, the break stress levels recovered to earlier levels at $0.68 \mathrm{MPa}$ and break strain increased to $760 \%$. The stress in the phase separated SIPN material is shared by the two networks. Even as the substituted PHMS network fails, the high molecular weight SBA matrix with its entanglements allows the system further plastic deformation and possible stress induced orientation to re-attain better break stress and strain levels [29].

\subsection{Pervaporation results on 1,3-propanediol - water binary feed mixtures}

\subsubsection{The effect of amine loading in membrane}

Figure 4 illustrates the variation of steady state component fluxes and separation factors with increasing ACA functionalization. A decrease in steady state water flux, due to decreasing water 
affinity, was seen with increasing ACA functionalization in the membrane. The steep initial rise in the affinity of the membrane towards 1,3 PD plateaued with increasing ACA functionalization. A slight decrease in 1,3 PD flux with greater ACA loading may be attributed to increase of $\mathrm{Tg}$ and hence loss of chain flexibility impeding the diffusion of 1,3-PD molecules.

\subsubsection{Effect of process parameters: feed temperature, feed composition, cross flow velocity} The effect of process parameters was studied on the membrane structure SBA_90ACA, which allowed for long-term experiments on account of its better mechanical integrity. Figure 5a illustrates the effect of temperature on pervaporation performance. A slight increase in water and 1,3-PD flux is seen with temperature. The membrane selectivity reduces with temperature as seen from the separation factor. Increase in temperature enhances the diffusion of both components and to some extent offsets the predominance of the solubility of 1,3-PD over water controlling the overall permeability.

Figure 5a also illustrates the effect of 1,3-PD feed concentration at constant temperature and cross flow rate. While the water flux decreased and the 1,3-PD flux increased, the separation factor decreases with increase in the feed 1,3-PD concentration. The reduced selectivity may be attributed to plasticization and swelling of the membrane with increasing 1,3-PD concentration in the feed which allowed for a greater amount of both components to diffuse through and resulted in lower selectivity.

Figures $5 b$ and $5 c$ examine the effect of cross flow rate at three temperatures on the flux and separation factors. The feed 1,3-PD concentration was $10 \mathrm{~g} / \mathrm{l}$. Increase in the cross flow rate increased the components fluxes as well as the separation factors. The effect on selectivity enhancement with cross flow rate was more significant at $30{ }^{\circ} \mathrm{C}$ than it was at $50{ }^{\circ} \mathrm{C}$. Cross flow velocity is associated with concentration polarization. For permeating components that are enriched, the concentration polarization assumes values $<1$ and for components with high levels of enrichment it becomes the deciding factor in pervaporation performance. In these experiments, the enrichment achieved was fair and hence the concentration polarization and the transport coefficients of the static layer were not decisive in determining selectivity and component fluxes.

\subsection{Mass transport analysis}

\subsubsection{Overall mass transfer coefficient and permeability}


Pervaporation mass transport in nonporous dense membranes is often described by the solution diffusion mechanism where the diffusion is typically described by Fick's first law [30,31]. The driving force is the difference in activity or fugacity of the $i^{\text {th }}$ species given by Equation 3 .

$$
f_{i}=x_{i}^{*} \gamma_{i} P_{i}^{s a t}
$$

where $f$ is the fugacity, $x_{i}{ }^{*}$ is the mole fraction of the $i^{\text {th }}$ component in the feed at the membrane interface, $\gamma_{i}$ is the activity coefficient, $P_{i}^{\text {sat }}$ is the saturation pressure. The flux of the solute $\left(i^{\text {th }}\right.$ species) across the pervaporation membrane may be expressed as,

$$
J_{i}=\frac{p_{i}}{l}\left(x_{i}^{*} \gamma_{i} P_{i}^{s a t}-y_{i}^{*} P_{p}\right)
$$

where $J_{i}$ and $p_{i}$ are the flux and membrane permeability of the $i^{\text {th }}$ species, $l$ is membrane thickness, $y_{i}{ }^{*}$ is mole fraction of the vapor and $P_{p}$ is the total pressure at the permeate side of the membrane. The steady state flux can be expressed alternatively, as per Equation 5, in terms of concentration in bulk solution $[22,25]$.

$$
J_{i}=\frac{p_{i, o v}}{l}\left(x_{i} \gamma_{i} P_{i}^{s a t}-y_{i} P_{p}\right)
$$

where $p_{i, o v}$ is the overall permeability. The partial pressure on the permeate side, $y_{i} P_{p}$, upon application of vacuum, is neglected and thus the equation above becomes,

$$
J_{i}=\frac{p_{i, o v}}{l} x_{i} \gamma_{i} P_{i}^{s a t}=K_{i, o v} C_{i}
$$

where $K_{i, o v}$ is the overall mass transfer coefficient of solute $i$ and $C_{i}$ is the molar concentration in $\mathrm{kg}$ mole $/ \mathrm{m}^{3} . K_{i, o v}$ can be expressed as $p_{i, o v} \gamma_{i} \frac{P_{i}^{s a t}}{l C^{T}}$ where $C^{T}$ is the total molar concentration of the feed solution, and $C_{i}=x_{i} C^{T}$. Eq.6 relates the species flux to the concentration of the respective species in the feed. Thus the component flux could be used to compute the overall mass transfer coefficient and overall permeability of 1,3-PD. Activity coefficients of the feed concentrations were computed by the Wilson equation and saturation vapor pressure by the Antoine equation [30]. The overall 1,3-PD mass transfer coefficients and permeabilities are shown in Table 1. All computed data shown is based on experiments with a feed 1,3-PD concentration of $10 \mathrm{~g} / \mathrm{l}$. The data for the membranes shown are those for the SBA_90ACA membrane. Data for other membranes was also generated at a volumetric cross flow rate of $31.9 \mathrm{~L} / \mathrm{h}$. The variations with temperature follow the same pattern as reported for SBA_90CA in Table 1. 


\subsubsection{Boundary layer and membrane mass transfer coefficients}

Concentration polarization adversely affects the separation performance due to the build up of a liquid side boundary layer whose resistance adds to the intrinsic membrane resistance. In severe cases, measured separation factors can be as low as $10 \%$ of the intrinsic separation factors [32]. The boundary layer mass transfer coefficient can sometimes be obtained by semi-empirical correlations of the form [33,34],

$$
S h \propto \operatorname{Re}^{n} S c^{q}
$$

where $S h$ is the Sherwood number. It is equal to $k_{P D}^{B L} \frac{d_{H}}{D}, k_{P D}^{B L}$ is the mass transfer coefficient of 1,3-PD through the liquid boundary layer in $\mathrm{m} / \mathrm{s}, D\left(\mathrm{~m}^{2} / \mathrm{s}\right)$ is the diffusivity of 1,3-PD in water (computed from the Wilke - Chang equation [34]), and $d_{H}(\mathrm{~m})$ is a characteristic dimension of the membrane channel given by $\frac{2 W h}{W+h}, W$ and $h$ being the width and height of the channel. Re is the Reynolds number, equal to $d_{H} \mathrm{v} / v$, where $\mathrm{v}$ is the mean linear velocity in $\mathrm{m} / \mathrm{s}$ and $v$ is the kinematic viscosity in $\mathrm{m}^{2} / \mathrm{s}$ at the respective temperature $[32,35,36] . S c$ is the Schmidt number and is equal to $v / D$. The exponent $n$ typically varies from 0.5 to 1 depending upon geometry and flow regime (laminar or turbulent) and the exponent $q$ is typically $1 / 3$.

In the case here, an accurate correlation is not well known due to the large variation in local Re as the flow expands into the circular membrane channel and then contracts towards the outlet end of the channel. Nevertheless, Eq.7 provides guidance to constrain the regression results below used to obtain the boundary layer and membrane mass transfer coefficients. Rearranging Eq.7 in terms of $k_{P D}^{B L}$ and the experimental variables of feed flow, $F$, and temperature, $T$, the boundary layer mass transfer coefficient should be correlated as

$$
k_{P D}^{B L}=M F^{n} T^{m}
$$

where $M$ is a constant, $n$ is the same exponent as in Eq.7 and $m$ is an exponent obtained by combining the temperature effects on $D$ and $v$ that arise in their various occurrences in the $S h, \operatorname{Re}$ and $S c$ numbers. Therefore, the value of $\mathrm{n}$ is expected to lie in the range 0.5 to 1 , and $\mathrm{m}$ is expected to be near zero since the temperature effects largely cancel, for liquids, when Eq.7 is rearranged to Eq.8. 
A simple resistance in series model to relate the overall mass transfer coefficient, $K_{P D, o v}$, to $k_{P D}^{B L}$ and the membrane mass transfer coefficient can be expressed as,

$$
\frac{1}{K_{P D, o v}}=\frac{1}{k_{P D}^{B L}}+\frac{1}{k_{m}{ }^{\prime}}
$$

where $k_{m}$ ' is the mass transfer coefficient of the 2-layer membrane synthesized for the experiments above. Membrane mass transfer coefficients are typically expressed as an intrinsic material mass transfer coefficient with units $\mathrm{m}^{2} / \mathrm{s}$ and then divided by the membrane thickness to give a mass transfer coefficient with units of $\mathrm{m} / \mathrm{s}$. Since the membrane consists of two layers which requires further analysis, $k_{m}$ ' is used in Eq.9 to denote the combined membrane mass transfer coefficient. Inserting Eq.8 into Eq.9 gives,

$$
\frac{1}{K_{P D, o v}}=\frac{1}{M F^{n} T^{m}}+\frac{1}{k_{m}{ }^{\prime}}
$$

which has 4 unknowns, $M, n, m$, and $k_{m}$ '. The experiments above were conducted at 3 temperatures and $k_{m}$ ' may change with temperature, yielding a data regression problem with 6 unknowns: $M, n, m, k_{m}{ }^{\prime}\left(30^{\circ} \mathrm{C}\right), k_{m}{ }^{\prime}\left(40^{\circ} \mathrm{C}\right)$, and $k_{m}{ }^{\prime}\left(50^{\circ} \mathrm{C}\right)$. The 12 measurements of $K_{P D, o v}$ at 4 flows and 3 temperatures provides an over-determined data set suitable for regression to find best fit values of the 6 unknowns.

The results of the regression are given in Table 2. The best fit results yielded a relative error in the calculated values of $K_{P D, o v}$ of less than $8 \%$ compared to the experimental measurements. This fit is well within experimental uncertainty. Moreover, the values of the exponents $n$ and $m$ lie in the expected ranges, with $n=0.72, m=0$, and $M=0.97$. The best fit values of the combined membrane coefficient, $k_{m}$ ', are somewhat larger than $K_{P D, o v}$ as required, and the values of $k_{P D}^{B L}$ range from $5 \times 10^{-7} \mathrm{~m} / \mathrm{s}$ to about $18 \times 10^{-7} \mathrm{~m} / \mathrm{s}$. In all cases, $k_{P D}^{B L}>k_{m}{ }^{\prime}$, indicating that the majority of mass transfer resistance is in the membrane.

\subsubsection{Concentration polarization modulus}

The resistance to mass transfer in the boundary layer can be expressed in terms of the concentration polarization, $C_{p}$, defined as the ratio of the enrichment of 1,3-PD, $E_{P D}$, to the enrichment that would be obtained in the absence of boundary layer resistance, $E_{o, P D}$. The Baker model [32] can be expressed to relate these enrichment factors to the boundary layer mass transfer coefficient, $k_{P D}^{B L}$, 
where $J_{v}$ is the convective fluid velocity towards the membrane surface caused by the mass transfer, and $J_{v}=J / C^{T}$, with $J$ equal to the total molar flux across the membrane. Using the measured fluxes and concentrations (Fig.5), and the computed boundary layer mass transfer coefficients (Table 2), the concentration polarization for the SBA_90ACA membrane, with varying cross-flow velocity and a feed 1,3-PD concentration of 10g/l, is shown in Figure 6a. With values ranging from 0.75 to $0.95, C_{p}$ indicates that the boundary layer resistance was significant at low cross flows but became of very little importance at the higher cross flows. In all cases, the major resistance to mass transfer lies in the membrane and not in the boundary layer, even though the Reynolds numbers are in the laminar flow regime range of $72-400$. Concentration polarization plays an important role in cases when the intrinsic enrichments are > 100. In these experiments the computed intrinsic enrichment factors lay between 12 and 15. This, and the limited mass uptake of 1,3-PD in the membrane are the reason for the relatively small role of the boundary layer resistance and the predominance of the membrane in separation performance.

\subsubsection{The intrinsic mass transport coefficient of the membrane}

The membrane structure as shown in the FESEM image (Fig.2c) is schematically represented in Figure $6 \mathrm{~b}$. The figure also shows the permeation pathway for the diffusing components. The intrinsic membrane mass transport coefficient may be derived from the combined membrane mass transfer coefficient, $k_{m}$ ' and the geometric characteristics of the membrane. The geometric characteristics of importance are the total membrane thickness, $z_{2}=643$ microns, the thickness of the top dense layer, $z_{1}=108$ microns, and the porosity of the polyethylene layer, $\xi=0.48$. Equating the mass transfer rates through the two layers leads to,

$$
k_{m}=k_{m} \cdot \bullet \frac{z_{2}-z_{1}(1-\xi)}{\xi}
$$

where $k_{m}$ is the intrinsic mass transfer coefficient of the membrane. The values of $k_{m}$ for the SBA_90ACA membrane based on experiments with a feed 1,3-PD concentration of $10 \mathrm{~g} / 1$ were: $1.68 \cdot 10^{-10} \mathrm{~m}^{2} / \mathrm{s}\left(30^{0} \mathrm{C}\right), 1.84 \cdot 10^{-10} \mathrm{~m}^{2} / \mathrm{s}\left(40^{0} \mathrm{C}\right)$ and $1.84 \cdot 10^{-10} \mathrm{~m}^{2} / \mathrm{s}\left(50^{0} \mathrm{C}\right)$. 


\subsection{Solubility parameters}

Permeation may be defined as $P=D \cdot S$, where $D$ is the diffusion coefficient and $S$ is the solubility for components into the membrane from the feed. The relative enrichment of components in a pervaporation feed occurs by virtue of their higher affinity for the membrane material or greater diffusivity or both [37]. The membrane-component affinity may be described by the Hansen solubility parameter comprising hydrogen bonding interactions $\left(\delta_{H}\right)$, polar interactions $\left(\delta_{P}\right)$ and dispersion interactions $\left(\delta_{D}\right)$ [21,37]. For a binary system, the Hansen solubility parameter distance $R_{a}$ is a measure of the dissimilarity between two components [38].

$$
R_{a}=\sqrt{4\left(\delta_{d 1}-\delta_{d 2}\right)^{2}+\left(\delta_{p 1}-\delta_{p 2}\right)^{2}+\left(\delta_{H 1}-\delta_{H 2}\right)^{2}}
$$

The chemistry of the membrane and its interaction with permeating components affects $R_{a}$ and the separation performance $[39,40]$. Water has the highest $\delta_{P}$, closely followed by glycols, such as 1,3-PD [21]. Water also possesses the highest $\delta_{H}$ also closely followed by glycols [21]. Large differences between $\delta_{H}$ for water and organic solvents makes their pervaporative dehydration feasible and efficient [21, 40]. Additionally, the diffusive efficacy of components through a membrane depends upon their kinetic diameter $\left(\mathrm{d}_{\mathrm{k}}\right)$, which considers the molecular size and shape [21,39]. Given that the $d_{k}$ of water is significantly lower than that of 1,3-PD, it diffuses faster. Hence the onus of pervaporative enrichment in favor of 1,3-PD lies on preferential sorption of 1,3-PD into the membrane and the concomitant rejection of water [21]. The proximity of the solubility parameters of water and 1,3-PD compounds the difficulty of separation using conventional membrane materials such as PDMS and hence calls for its functionalization. The chemistry of functionalization, while enhancing the affinity for 1,3-PD must also make the membrane more hydrophobic and this is reflected in the partial solubility parameters.

The partial solubility parameters of water and 1,3-PD were obtained from literature [40-42]. The $\delta_{H}$ for PDMS were obtained from literature while $\delta_{p}$ and $\delta_{D}$ computed from the refractive index and dipole moments respectively [41-43]. Those of ACA were computed using a group contribution method [44], employing two kinds of characteristic groups: first-order groups that describe the basic molecular structure of compounds and second-order groups based on the conjugation theory to improve the accuracy of predictions. The contribution towards $\delta_{H}, \delta_{p}$ and 
$\delta_{D}$ were computed from literature values provided for the participating groups and identifiable conjugates in ACA [44]. In the absence of the availability of reliable $\delta_{H}, \delta_{p}$ and $\delta_{D}$ group contributions for $\mathrm{Si}-\mathrm{O}, \mathrm{Si}-\mathrm{H}$ and $\mathrm{Si}-\mathrm{CH}_{3}$ the partial solubility parameters for the ACA modified siloxane materials could not be computed. TEAS parameters or fractional parameters, were computed from the partial interaction parameters and indicate a fractional contribution of each partial parameter to the whole solubility parameter. They are defined as

$$
\begin{gathered}
f_{D}=\frac{\delta_{D}}{\delta_{D}+\delta_{H}+\delta_{p}} \\
f_{H}=\frac{\delta_{H}}{\delta_{D}+\delta_{H}+\delta_{p}} \\
f_{p}=\frac{\delta_{p}}{\delta_{D}+\delta_{H}+\delta_{p}}
\end{gathered}
$$

The TEAS parameters are illustrated in Fig 6 (c). The distance of separation between 1,3-PD and water is similar to that between 1,3-PD and ACA. Thus 1,3-PD can be only partly partitioned into ACA, while the hydrophobic character of ACA is underscored by its large separation distance from water, due primarily to the disparities in $\delta_{H}$ and $\delta_{p}$. While two materials may end up with the same solubility parameters, computed arithmetically, the individual contributions that make up this value may be different with ramifications on their mutual affinity [45]. The behavior of unfunctionalized siloxane PDMS is dominated by dispersion forces with very little polar and hydrogen bonding based affinity for 1,3-PD as well as water [21]. The distances of separation from water for both ACA and siloxanes are comparable. When the siloxane is functionalized with ACA, which is the major component in the membrane matrix fabricated by either scheme, the affinity for 1,3-PD increases while that for water remains practically unchanged.

Permeant transport through membranes with strong membrane-species interactions has been visualized to occur either by random walk or by jumps from one interactive site to another [46]. Unfunctionalized PDMS has very little affinity for either water or 1,3-PD. When functionalized, all its interaction parameters with 1,3-PD are superior to those with water. In light of the transport theory, the movement of 1,3-PD through the membrane may be thought of as a random walk supported by a balance between polar interactions and dispersion interactions with functional groups on ACA and siloxane chains. In an alternative theory, the permeants are 
thought to cluster around given functional groups [32, 37]. With a binary feed, when one permeant molecule jumps from one cluster, the vacancy left behind may be filled up by a permeant molecule of either species [46]. In this system, the filling of this vacancy may be selective, pertinent to the interaction parameters allowing for a greater absorption and permeation of 1,3-PD than water.

The classical solution diffusion model used here is valid only for non-swollen membranes. In cases where appreciable swelling occurs, the partition and diffusion coefficients become concentration dependent and the theory must be modified to adapt to these changes and also to define the effect of coupled transport in multicomponent pervaporations with model fermentation broths [37].

\subsection{Comparative performance analysis}

The paragraphs below provide an overview of the comparative performance of systems that have been employed to enrich 1,3-PD from aqueous mixtures and broth compositions. This includes earlier pervaporation experiments on zeolite membranes, which were successful in separating 1,3-PD from broth components other than water. While the pervaporative zeolite membranes achieved separation of 1,3-PD from other broth components, the membranes were not selective for 1,3-PD over water [16, 17]. The ionic liquid SLM reported separation factors greater than 100 for 1,3-PD in batch pervaporation in a nano-porous module of $\sim 1000 \mu$ thickness. While a stability of 9 months was claimed in this particular work [18], SLMs typically suffer long-term stability issues on account of leaching. Additional limitations include fabrication of membrane modules and scale up.

Hydrolytic instability of many ionic liquids limit their applications to anhydrous conditions [47]. The requirement for hydrolytically stable ionic liquids has resulted in several developments, yet their technical applications are limited by the high price of the anions [47]. A brief comparison of the price of materials developed in this work versus that used for the cyanoborate ionic liquid based membrane [18] was carried out with current retail price data from Sigma Alridch (www.signmaaldrich.com), Oakwood Chemicals Inc. (http://www.oakwoodchemical.com) and Fluorochem Ltd. (http://www.fluorochem.co.uk). A simple stoichiometric computation based on the molecular weights and the prices of the individual moieties making up the compound reveals that the cyanoborate ionic liquid costs $\$ 36,004 /$ mole, while the ACA functionalized PHMS 
materials cost $\$ 1133 / \mathrm{mol}$, $\$ 892 / \mathrm{mol}$ and $\$ 655 / \mathrm{mol}$ for the $90 \%, 70 \%$ and $50 \%$ functionalized materials, respectively. The cost per unit weight of the ionic liquid is $\$ 120 / \mathrm{g}$, while those of the ACA functionalized siloxanes are $\$ 6 / \mathrm{g}, \$ 5.6 / \mathrm{g}$ and $\$ 4.9 / \mathrm{g}$ for $90 \%, 70 \%$ and $50 \%$, respectively. Price/performance trade off estimates can be generated using either the molar prices or the mass prices in terms of the separation factors. The 1,3-PD flux obtained in this work is also 1.5 times higher than that reported with the cyanoborate ionic liquid.

A preliminary estimation was made of the total volume of membrane material required to enrich a flow of $100 \mathrm{~g} / \mathrm{h}$ of feed with 1 mass $\%$ 1,3-PD to a final 1,3-PD concentration of $>90 \%$. The separation factor and flux of 1,3-PD was assumed constant in each enrichment stage. This assumption is an oversimplification but quite adequate for a rough comparison. The average separation factor for the SBA_90ACA membrane was taken as 14 at an average 1,3-PD flux of $5.89 \mathrm{~g} / \mathrm{m}^{2} \mathrm{~h}$. The computation indicated that 3 enrichment steps with a total membrane area of $4650 \mathrm{~cm}^{2}$ are required. The membrane volume was estimated by taking into consideration that the 550 micron thick porous polyethylene support has a porosity of $48 \%$ and the dense layer thickness is 108 microns. Thus, the required volume is $169 \mathrm{~cm}^{3}$. Also assuming an approximate density of $1 \mathrm{~g} / \mathrm{cm}^{3}$, the cost of the material required to achieve the aforementioned enrichment level is $\sim \$ 1015$.

The same computation was carried out for the cyanoborate ionic liquid membrane stabilized in a nanoporous ceramic module. The flux of 1,3-PD $\left(3.86 \mathrm{~g} / \mathrm{m}^{2} \mathrm{~h}\right)$ and separation factor (177) reported [18] were assumed constant for the computation. The same enrichment levels from a starting composition of 1\% 1,3-PD was calculated to require 2 enrichment steps with a total area of $4660 \mathrm{~cm}^{2}$. The thickness of the module reported in their work [48] is $3 \mathrm{~mm}$ (with a $7 \mathrm{~mm}$ inner diameter and $10 \mathrm{~mm}$ outer diameter). The nanoporous module reported in their work has a porosity of $30 \%[18,48]$. Thus, the total cyanoborate ionic liquid requirement is $419 \mathrm{~cm}^{3}$. Assuming a density of $1 \mathrm{~g} / \mathrm{cm}^{3}$, the cost of material required to achieve the same enrichment level is $\sim 50,328$. Although this rough calculation indicates a very large difference in material costs, production costs for the SBA_90ACA membrane, optimization of the SLM design and a large reduction in the cost of the cyanoborate ionic liquid may mitigate this difference.

The work reported here reacts a 1,3-PD solvent, ACA, into a siloxane backbone. The membrane, with its mechanical integrity, allows the flexibility of fabrication into structures and modules. 
While fair separation was achieved for the structure reported in this paper, the structure provides a pathway for scale up with design flexibility to optimize the cost/performance tradeoff. Membrane structures can be envisioned wherein a thin surface layer of highly ACA functionalized membrane is followed by support layers with enhanced flux while making no adverse contribution towards the separation efficacy.

\section{Conclusions}

The paper reports an ACA functionalized siloxane membrane for the pervaporative enrichment of 1,3-PD concentration from binary aqueous solutions. The functionalized siloxane materials were crosslinked by two mechanisms with superior mechanical stability being obtained with the phase separated blend. The separation factors increased with increasing functionalization. The feed concentration and temperature also played an important role in determining separation efficacy. A minimal amount of concentration polarization was observed as is the norm for such systems with fair separation factors, with the resistance to permeation being dominated by the membrane. The solution diffusion model was used to compute the overall mass transfer coefficient of the membrane and the intrinsic mass transfer of the functionalized material. An analysis of the Hansen solubility parameters was carried out to explain the results obtained.

\section{Acknowledgements}

The authors acknowledge the advice of Prof. M.T. Shaw, (Professor Emeritus, University of Connecticut) in thermodynamic computations. Portions of this work were supported by DOE Grant DE-EE0003116.

\section{References}

1. A.J. Ragauskas, C.K. Williams, B.H. Davison, G. Britovsek, J. Cairney, C.A. Eckert, W.J. Frederick Jr., J.P. Hallett, D.J. Leak, C.L. Liotta, J.R. Mielenz, R. Murphy, R. Templer, T. Tschaplinski, The path forward for biofuels and biomaterial, Science. 311 (2010) 484-489.

2. Z.L. Xiu, A.P.Zeng, Present state and perspective of downstream processing of biologically produced 1,3-propanediol and 2,3-butanediol, Appl Microbiol Biotechnol. 78 (2008) 917-926.

3. R.K. Saxena, P. Anand, S. Saran, J. Isar, Microbial production of 1,3-propanediol: Recent developments and emerging opportunities, Biotechnology Advances. 27 (2009) 895-913. 
4. A.P. Zeng, H. Biebl, Bulk chemicals from biotechnology: the case of 1,3-propanediol production and the new trends, in: T. Scheper, K. Schugerl, A.P. Zeng (Eds.), Advances in biochemical engineering and biotechnology, Vol. 74, Springer-Verlag, Berlin, Heidelberg, New York, 2002, pp239-59.

5. A. Triguero, R. Blanco, H. Machado, M. Rodríguez, Evaluation of liquid extraction potentials for downstream separation of 1,3-propanediol, Biotechnology Techniques. 13 (1999) 127-130.

6. T.T. Ames, Process for the isolation of 1,3-propanediol from fermentation broth. US Patent 6361983 B1 (2002).

7. Y. Gong, Y. Tong, X.L. Wang, D.H. Liu, The possibility of the desalination of actual 1,3-propanediol fermentation broth by electrodialysis, Desalination. 161 (2004) 169-178.

8. J. Hao, D.H. Liu, Desalination of fermented broth containing 1,3-propanediol by electrodialysis, Chinese J Proc Eng. 5 (2005) 36-39.

9. Z. Li, B. Jiang, D. Zhang, Z. Xiu, Aqueous two-phase extraction of 1,3-propanediol from glycerol-based fermentation broths, Separation and Purification Technology. 66 (2009) 472-478.

10. A. Baiada, A. Vitner, R.P. Jansen, A.M. Baniel, Process for producing 1, 3propanediol. US Patent 7056439 B2 (2006).

11. A.K. Hilaly, T.P. Binder, Method of recovering 1,3-propanediol from fermentation broth. US Patent 6479716 B2 (2002)

12. M.H. Cho, S.I. Joen, S.H. Pyo, S. Mun, J.H. Kim, A novel separation and purification process for 1,3-propanediol, Process Biochem. 41 (2006) 739-744.

13. P. Anand, R.K. Saxena, R.G. Marwah, A novel downstream process for 1,3propanediol from glycerol-based fermentation, Appl. Microbiol. Biotechnol. 90 (2011) $1267-1276$.

14. J. Hao, F. Xu, H. Liu, D. Liu, Downstream processing of 1,3-propanediol fermentation broth, Journal of Chemical Technology and Biotechnology.81(2006) 102108.

15. J.J. Malinowski, Reactive Extraction for Downstream Separation of 1,3-Propanediol, Biotechnology Progress. 16 (2000) 76-79.

16. S. Li, V.A. Tuan, J.L. Falconer, R.D, Noble, Separation of 1,3- propanediol from glycerol and glucose using a ZSM-5 zeolite membrane, J. Membr Sci. 191 (2001a) 5359.

17. S. Li, V.A. Tuan, J.L. Falconer, R.D. Noble, Separation of 1,3- propanediol from aqueous solutions using pervaporation through an X-type zeolite membrane, Ind Eng Chem Res 40 (2001b) 1952- 1959. 
18. P.Izák, M. Köckerling, U. Kragl, Stability and selectivity of a multiphase membrane, consisting of dimethylpolysiloxane on an ionic liquid, used in the separation of solutes from aqueous mixtures by pervaporation, Green Chem. 8 (2006) 947-948.

19. S.Y. Li, R. Srivastava, R.S. Parnas, Study of in situ 1-Butanol Pervaporation from AB-E Fermentation Using a PDMS Composite Membrane: Validity of Solution-Diffusion Model for Pervaporative A-B-E Fermentation, Biotechnol. Prog. 27 (2011) 111-120.

20. S. Krishnan, C.J. Weinman, C.K. Ober, Advances in polymers for anti-fouling surfaces, J. Mater.Chem. 18 (2008) 3405 - 3413.

21. P. Shao, R.Y.M. Huang, Polymeric membrane pervaporation, Journal of Membrane Science. 287 (2007) 162-179.

22. S. Li, R. Srivastava, R.S. Parnas, Separation of 1-butanol by pervaporation using a novel tri-layer PDMS composite membrane, J. Membr. Sci. 363 (2010) 287-294.

23. P.Wu, R.W.Field, R.England, B.J.Brisdon, Performance of PDMS and organofunctionalised PDMS membranes for the pervaporative recovery of organics from aqueous streams, J. Membr. Sci. 137 (1997) 63-88.

24. P.Wu, R.W.Field, R.Englanda, B.J. Brisdon, A fundamental study of organofunctionalised PDMS membranes for the pervaporative recovery of phenolic compounds from aqueous streams, J. Membr. Sci. 190 (2001) 147-157.

25. P. Wu, B.J. Brisdon, R. England, R.W. Field, Preparation of modified difunctional PDMS membranes and a comparative evaluation of their performance for the pervaporative recovery of p-cresol from aqueous solution, J. Membr. Sci. 206 (2002) $265-275$.

26. C.B. Mallon, B.Mead, Surfactant free process for production of pressure sensitive adhesive latexes. US Patent 4316830 (1982).

27. M. Ma, R.M. Hill, J.L. Lowery, S.V. Fridrikh, G.C. Rutledge, Electrospun Poly(Styrene-block-dimethylsiloxane) Block Copolymer Fibers Exhibiting Superhydrophobicity, Langmuir. 21 (2005) 5549-5554.

28. P. Roach, N.J. Shirtcliffe, M.I. Newton, Progress in superhydrophobic surface development, Soft Matter. 4 (2008) 224-240.

29. J. Sun, X. Zhao, W. R. K. Illeperuma, O. Chaudhuri, K.H.Oh, D.J. Mooney, J.J. Vlassak, Z. Suo, Highly stretchable and tough hydrogels, Nature. 489 (2012) 133-136.

30. J.G. Wijmans, R.W.Baker, The solution Diffusion model: a review, J. Membr.Sci. 107 (1995) 1-21.

31. S.J. Lue, W.W. Chen, S.Y. Wu, L.D. Wang, Vapor permeation modeling of multicomponent systems using a poly(dimethylsiloxane) membrane, J. Membr. Sci. 311 (2008) 380-389. 
32. R.W. Baker, J.G. Wijmans, A.L. Athayde, R. Daniels, J.H. Ly. M. Le, The effect of concentration polarization on the separation of volatile organic compounds from water by pervaporation, J. Membr. Sci. 137 (1997) 159-172.

33. C. Lipski, P. Côté, The use of pervaporation for the removal of organic contaminants from water, Environmental Progress. 9 (1990) 254-261.

34. C.R. Wilke, P. Chang, Correlation of diffusion coefficients in dilute solutions AICHE Journal. 1, (1955) 264-270.

35. M.T. Sanz, B. Blanco, S. Beltran, J.I. Cabezas, Vapor liquid equilibria of binary and ternary systems with water, 1,3-propanediol and glycerol, J Chem Eng Data. 46 (2001) 635-639.

36. D.M. Bajić, G.R. I.Zoran, P. Visak, E.M. Živković, S.P. Šerbanović, M.L. Kijevčanin. Densities, viscosities, and refractive indices of the binary systems (PEG200 + 1,2-propanediol, +1,3-propanediol) and (PEG400 + 1,2-propanediol, +1,3-propanediol) at (288.15 to 333.15$) \mathrm{K}$ and atmospheric pressure: Measurements and modeling, J. Chem Thermodynamics. 57 (2013) 510-529.

37. M. Mulder, T. Franken, C.A. Smolders, Preferential sorption versus preferential permeability in pervaporation, J. Membr. Sci. 22 (1985) 155-173.

38. D.J. Benedict, S.J. Parulekar, S.P. Tsai, Pervaporation assisted esterification of lactic and succinic acids with downstream ester recovery, J. Membr. Sci. 281 (2006) 435-445.

39. W.J.Koros, Membranes: Learning a lesson from nature, Chem Eng. Prog. 91 (1995) $68-81$.

40. C.M. Hansen, Hansen solubility parameter: A users handbook, second ed., CRC press Taylor and Francis group, Boca Raton, London, New York, 2007.

41. M. Alizadeh, F. Abbassi, M. Farahi, K. Jalili, Silicone based hydrogels prepared by interpenetrating polymeric network synthesis: Swelling properties and confinements effects on the formation kinetics, J appl Poly Sci. 124 (2012) 985-992.

42. J.N. Lee, C. Park, G.M. Whitesides, Solvent Compatibility of Poly(dimethylsiloxane)-Based Microfluidic Devices, Anal Chem. 75 (2003) 6544-6554.

43. N.A.Diachun, A.H. Marcus, D.M. Hussey, M.D.Fayer, Dynamics in Polydimethylsiloxane: The Effect of Solute Polarity, JACS. 116 (1994) 1027-1032.

44. E. Stefanis. C. Panayiotou, Prediction of Hansen Solubility Parameters with a New Group-Contribution Method, Int J. Thermophys. 29 (2008) 568-585.

45. M. Oshikawa, N. Ogata, T. Shimidzu, Polymer membrane as a reaction field. III: Effect of membranes polarity on selective separation of water-ethanol binary mixtures through synthetic polymer membranes, J. Membr. Sci. 26 (1986) 107-113. 
46. R.Y.M. Huang, P. Shao, X. Feng, C.M. Burns, Pervaporation separation of water / isopropanol mixture using sulfonated poly(ether ether ketone) (SPEEK) membranes: transport mechanism and separation performance, J. Membr. Sci. 192 (2001) 115-127.

47. E. Kuhlman, S. Himmler, H. Giebelhaus, P. Wasserscheid, Imidazolium dialkylphosphates - a class of versatile, halogen-free and hydrolytically stable ionic liquids, Green Chem. 9 (2007) 233 - 242.

48. P. Izak, M. Köckerling, U. Kragl, Mehrphasen-Membran. German Patent DE102006024397 B3 (2007). 




(b)
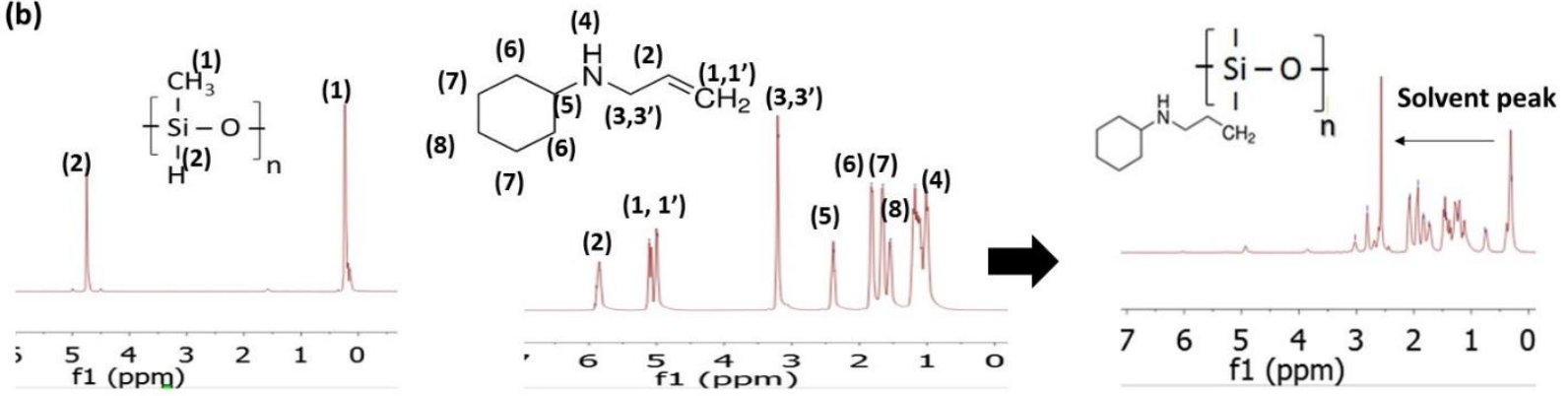

(c)

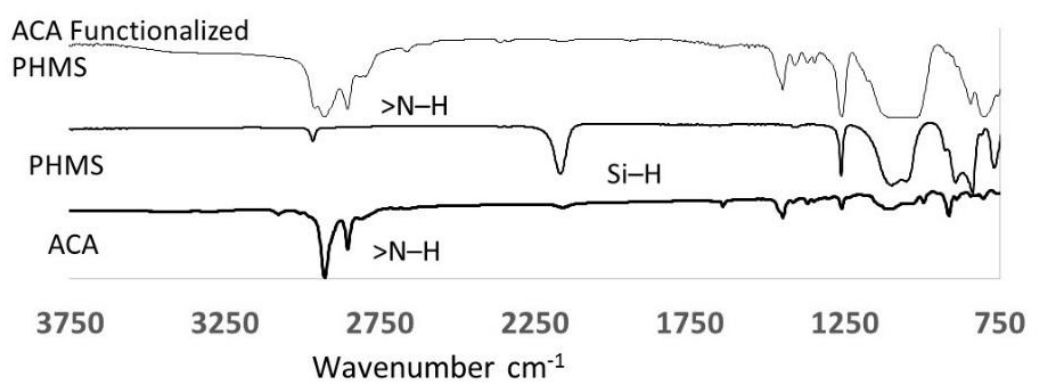

(d)

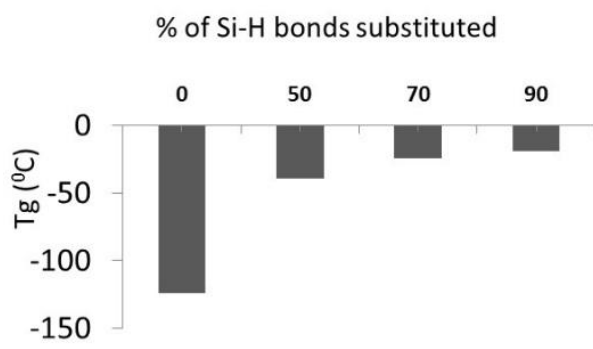

(e)

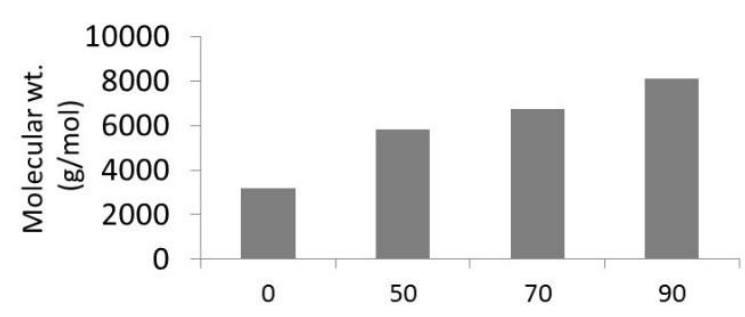

$\%$ of $\mathrm{Si}-\mathrm{H}$ groups substituted

Figure 1: (a) Hydrosilylation Reaction Scheme (b) Representative H1 NMR for hydrosilylation (c) Representative FTIR for hydrosilylation (d) Glass transition temperature at various levels of functionalization (e) Molecular weight at various levels of functionalization 
(a)

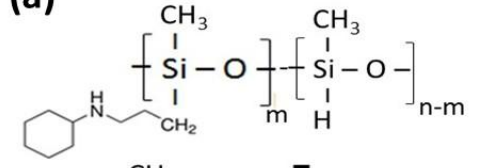
$\mathrm{HO}-\left[\begin{array}{c}\mathrm{SH}_{3} \\ \mathrm{Si}-\mathrm{O} \\ \mathrm{CH}_{3}\end{array}\right] \mathrm{NH}$
$\mathrm{Sn}$. Catalyst

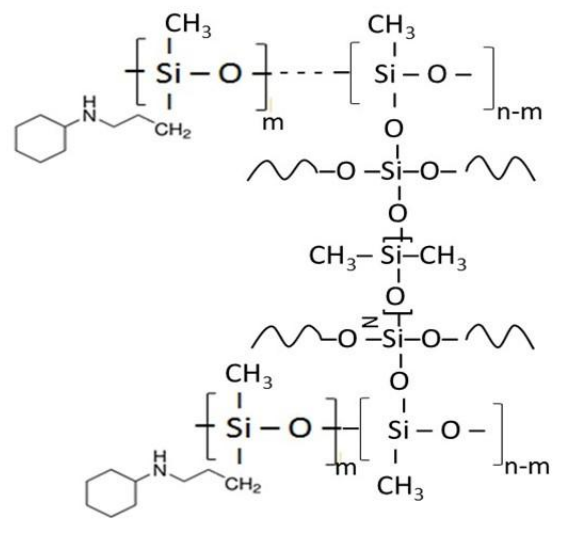

(b)

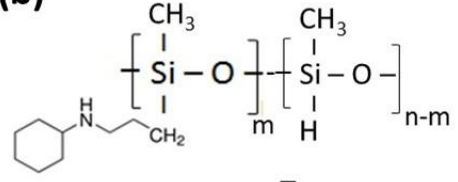

High Mwt. SBA Matrix $\mathrm{Si}(\mathrm{OEt})_{4}$ Sn. Catalyst

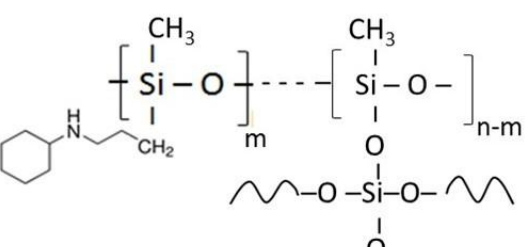
O<smiles>CCCCCO[Si](C)(C)OCCCC</smiles>

$\mathrm{CH}_{3}$

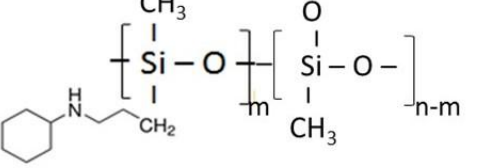

(c) Temperature $\left({ }^{\circ} \mathrm{C}\right)$

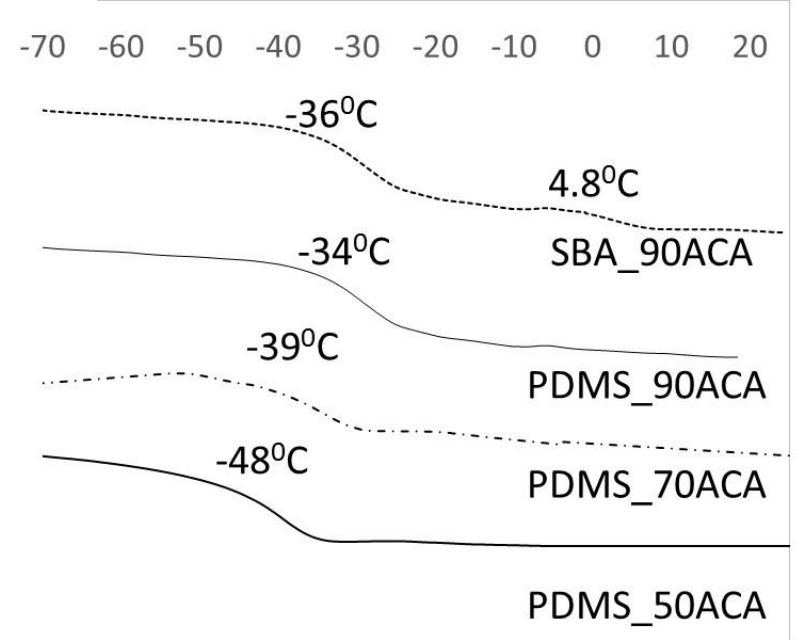

(d)

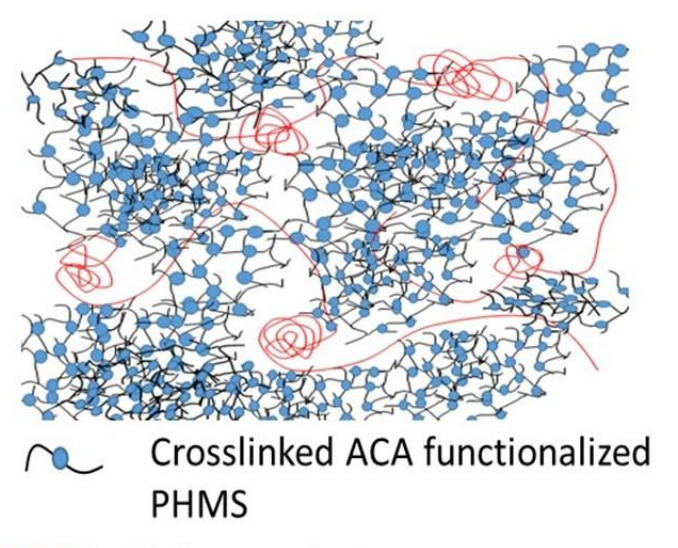

$\longrightarrow$ High Mwt. SBA

Figure 2: (a) Crosslinking reaction Scheme-1 (b) Crosslinking reaction Scheme-2 (c) Glass transition temperature of membrane forming recipes (d) Schematic representation of microphase segregated blend formed by scheme 2 . 


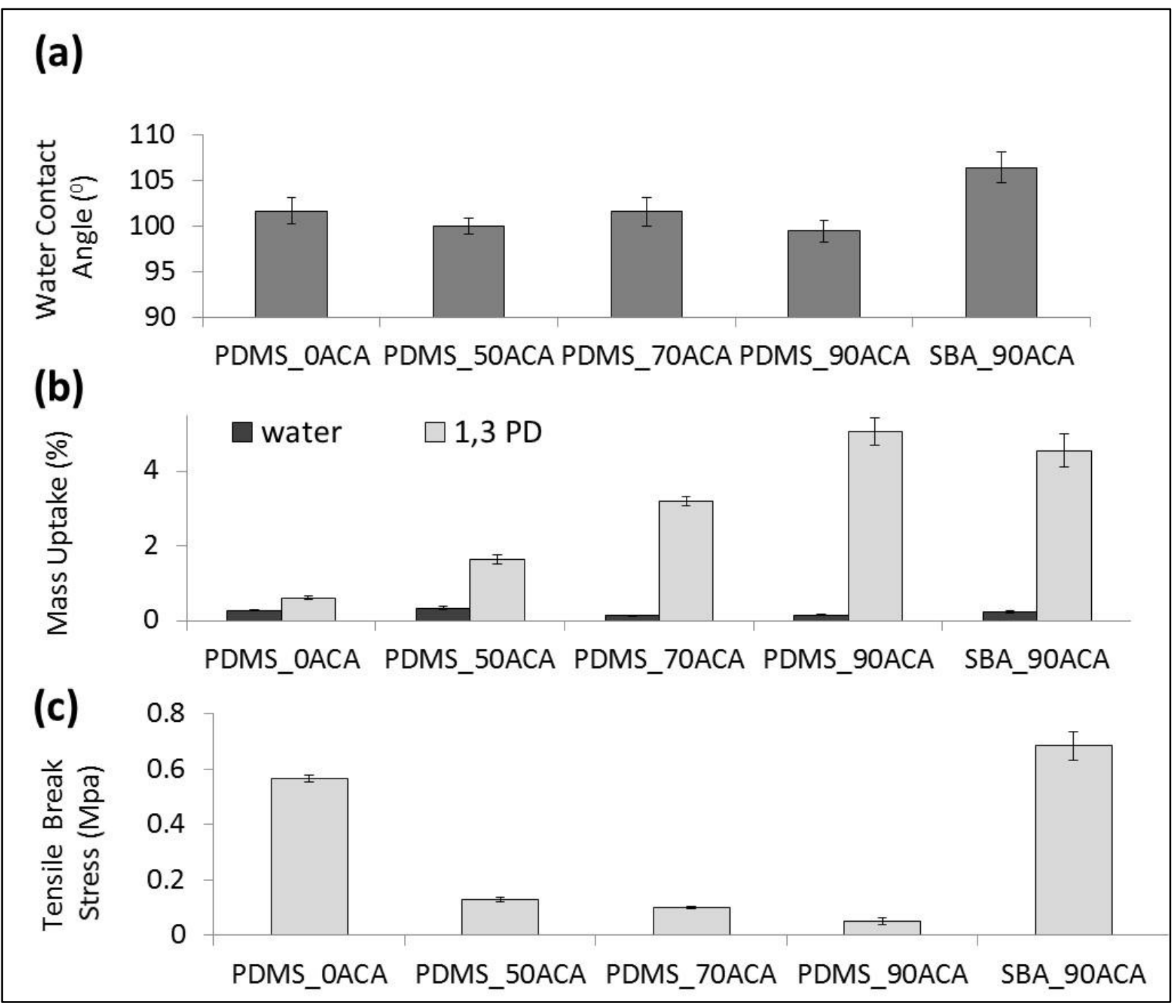

Figure 3: (a) Water contact angle on membrane forming recipes (b) Mass uptake results of membrane forming recipes (c) Tensile break stresses of membrane forming recipes. 


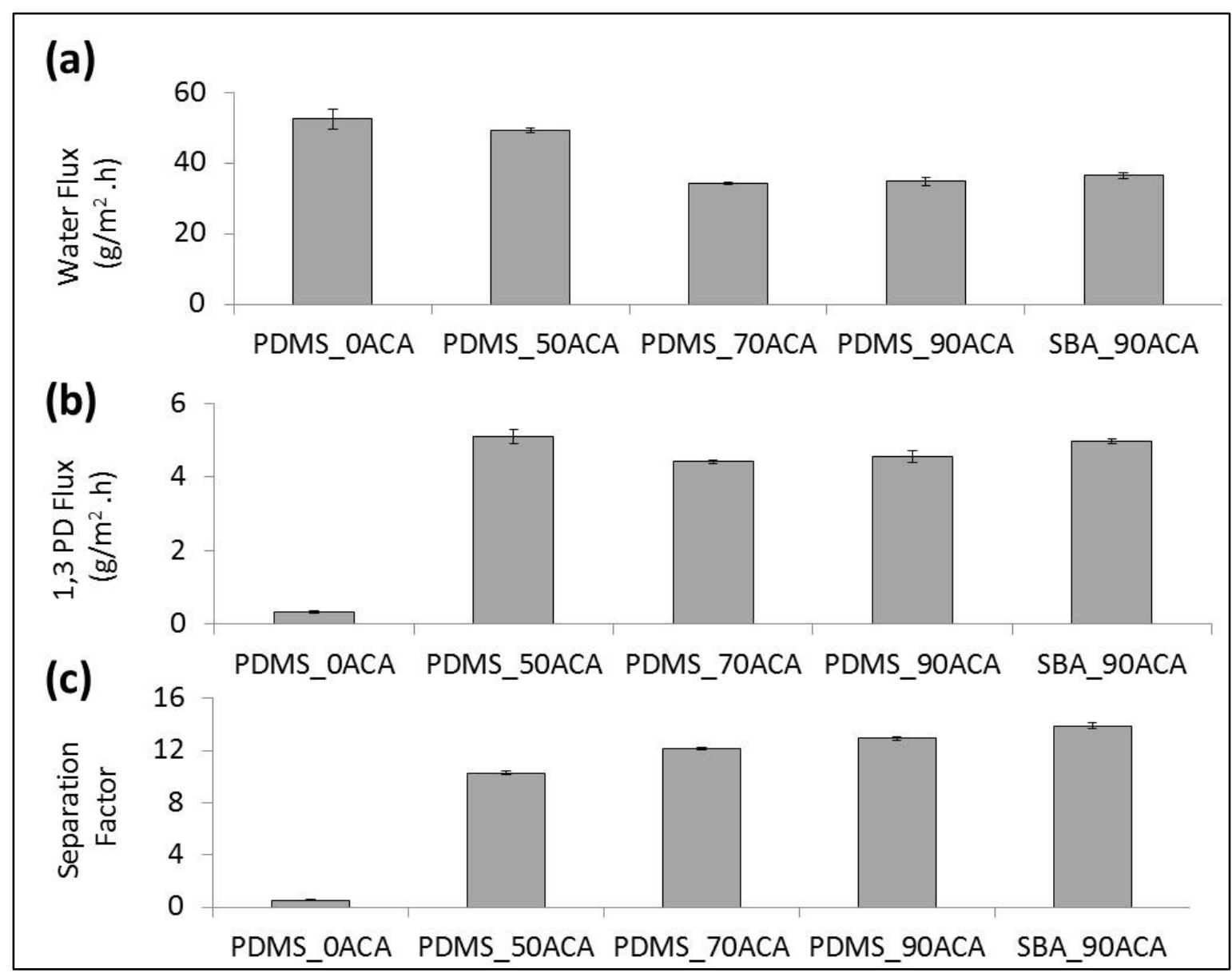

Figure 4: Variation of steady state component flux and separation factors with increasing ACA functionalization (a) Water Flux (b) 1,3-PD flux (c) Separation Factor 


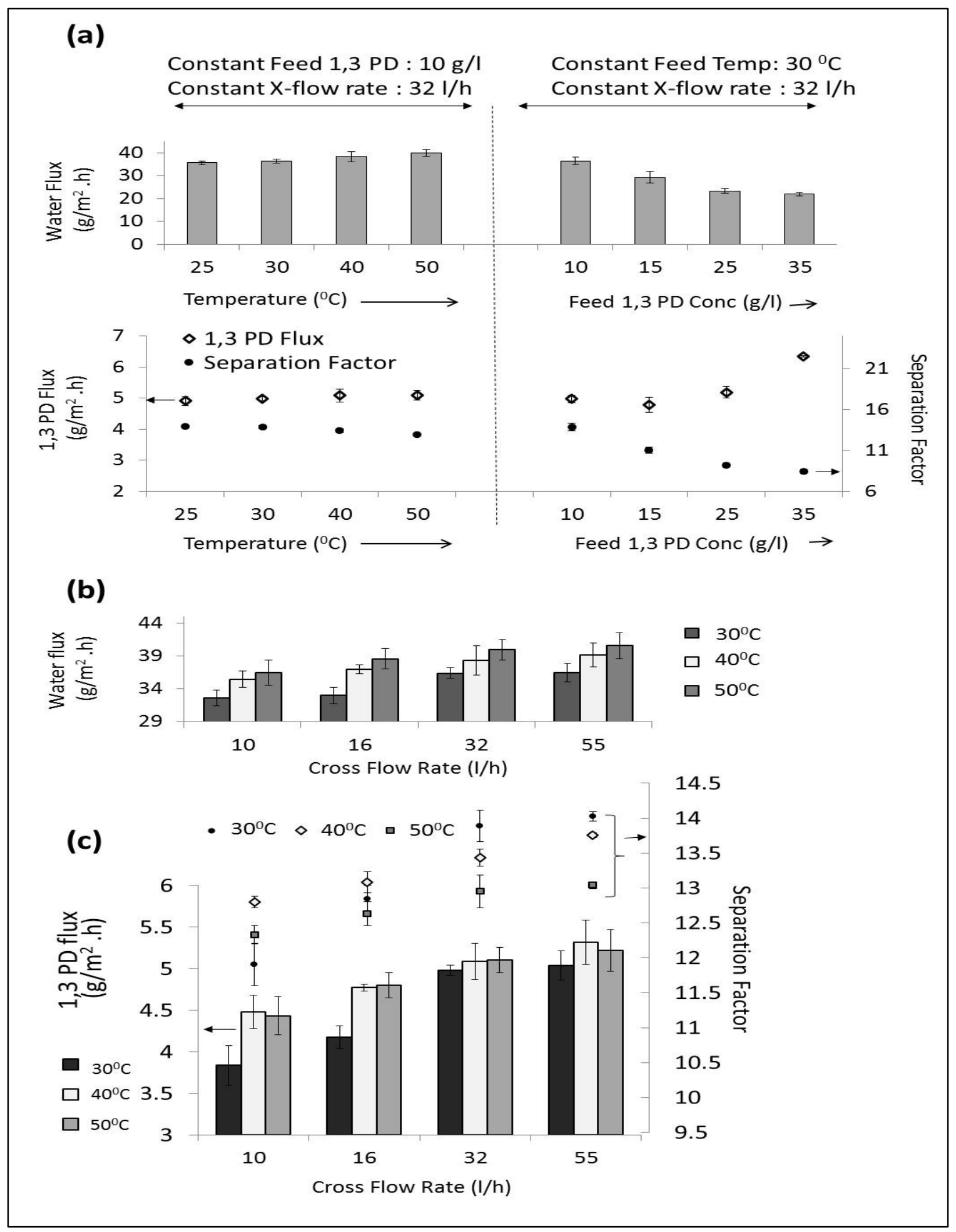

Figure 5: (a) Effect of feed 1,3-PD concentration and Feed Temperature (b) Effect of cross flow rate on water flux (c) Effect of cross flow rate on 1,3-PD flux and separation factors. 


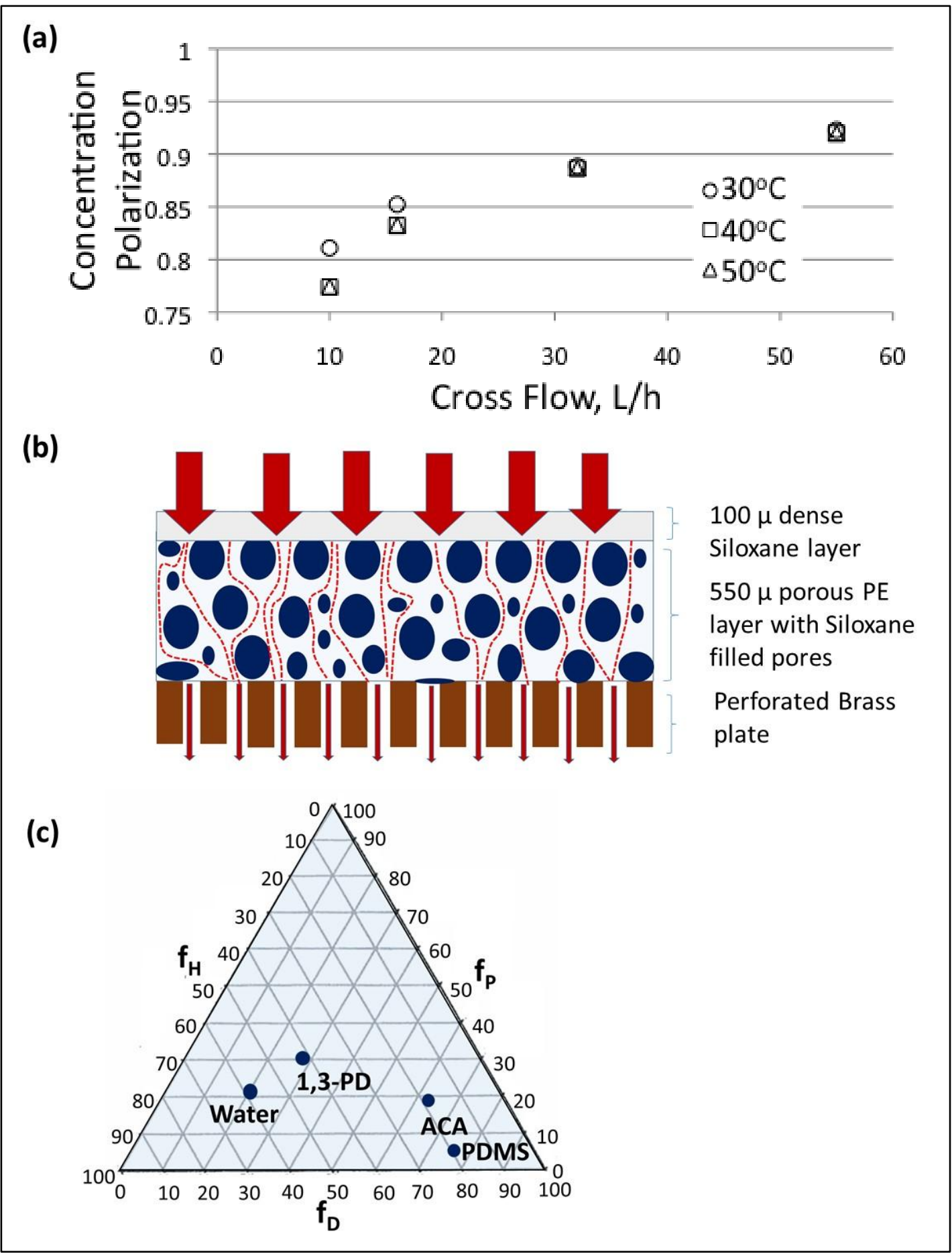

Figure 6: (a) Variation of Concentration Polarization modulus with cross flow rate and temperature at feed 1,3-PD concentration of $10 \mathrm{~g} / \mathrm{l}$ (b) Schematic of composite membrane structure showing the three layers. Permeation pathway is shown with red arrows and red dotted line (c) TEAS graph of the percentage contribution by the partial solubility parameters for each component. 
Table 1: 1,3 propanediol Mass Transfer Coefficient and Permeability at various temperatures for SBA_90ACA membrane

\begin{tabular}{|c|c|c|c|c|c|c|c|c|}
\hline $\begin{array}{l}\text { Cross Flow, } \\
\mathrm{L} / \mathrm{h}\end{array}$ & \multicolumn{2}{|r|}{9.9} & \multicolumn{2}{|c|}{16.3} & \multicolumn{2}{|c|}{31.9} & \multicolumn{2}{|c|}{54.5} \\
\hline $\begin{array}{l}\text { Reynolds } \\
\text { number }\end{array}$ & \multicolumn{2}{|r|}{72} & \multicolumn{2}{|c|}{121} & \multicolumn{2}{|c|}{233} & \multicolumn{2}{|c|}{400} \\
\hline $\begin{array}{c}\text { Temperature } \\
\text { (C) }\end{array}$ & $\begin{array}{c}\mathrm{K}_{\mathrm{ov}} \\
\mathrm{X} 10^{-7} \\
\mathrm{~m} / \mathrm{s}\end{array}$ & $\begin{array}{c}\mathrm{P}_{\mathrm{ov}} \\
\mathrm{X} 10^{-14} \\
\mathrm{kmol} / \mathrm{m} / \mathrm{Pa} / \mathrm{s}\end{array}$ & $\begin{array}{c}\mathrm{K}_{\mathrm{ov}} \\
\mathrm{X} 10^{-7}, \\
\mathrm{~m} / \mathrm{s}\end{array}$ & $\begin{array}{c}\mathrm{P}_{\mathrm{ov}} \\
\mathrm{X} 10^{-14} \\
\mathrm{kmol} / \mathrm{m} / \mathrm{Pa} / \mathrm{s}\end{array}$ & $\begin{array}{c}\mathrm{K}_{\mathrm{ov}} \\
\mathrm{X} 10^{-7}, \\
\mathrm{~m} / \mathrm{s}\end{array}$ & $\begin{array}{c}\mathrm{P}_{\mathrm{ov}} \\
\mathrm{X} 10^{-14} \\
\mathrm{kmol} / \mathrm{m} / \mathrm{Pa} / \mathrm{s}\end{array}$ & $\begin{array}{c}\mathrm{K}_{\mathrm{ov}} \\
\mathrm{X} 10^{-7}, \\
\mathrm{~m} / \mathrm{s}\end{array}$ & $\begin{array}{c}\mathrm{P}_{\mathrm{ov}} \\
\mathrm{X} 10^{-14} \\
\mathrm{kmol} / \mathrm{m} / \mathrm{Pa} / \mathrm{s}\end{array}$ \\
\hline 30 & 1.01 & 2.19 & 1.1 & 2.38 & 1.29 & 2.82 & 1.32 & 2.87 \\
\hline 40 & 1.18 & 2.55 & 1.25 & 2.72 & 1.31 & 2.9 & 1.4 & 3.03 \\
\hline 50 & 1.16 & 2.53 & 1.26 & 2.74 & 1.34 & 2.91 & 1.37 & 2.97 \\
\hline
\end{tabular}


Table 2: Boundary layer and combined membrane mass transfer coefficients

\begin{tabular}{|l|l|l|l|l|l|l|}
\hline & & $\mathrm{F}(\mathrm{L} / \mathrm{h})$ & 9.9 & 16.3 & 31.9 & 54.5 \\
\hline & & $\operatorname{Re}$ & 72 & 121 & 233 & 400 \\
\hline $\mathrm{T}\left({ }^{\circ} \mathrm{C}\right)$ & $\begin{array}{l}k_{m}{ }^{\prime} 10^{-7} \\
(\mathrm{~m} / \mathrm{s})\end{array}$ & $\begin{array}{l}k^{B L} 10^{-7} \\
(\mathrm{~m} / \mathrm{s})\end{array}$ & 5.1 & 7.2 & 11.7 & 17.3 \\
\hline 30 & 1.4 & & & & & \\
\hline 40 & 1.5 & & & & & \\
\hline 50 & 1.5 & & & & & \\
\hline
\end{tabular}

